\title{
DECREASED INFARCT SIZE AFTER FOCAL CEREBRAL ISCHEMIA IN MICE CHRONICALLY INFECTED WITH TOXOPLASMA GONDII
}

\author{
D. ARSENIJEVIC, ${ }^{a 1 *}$ F. DE BILBAO, ${ }^{b 1}$ P. VALLET, ${ }^{b}$ \\ A. HEMPHILL, ${ }^{c}$ B. GOTTSTEIN, ${ }^{c}$ D. RICHARD, ${ }^{d}$ \\ P. GIANNAKOPOULOS ${ }^{b}$ AND W. LANGHANS ${ }^{\mathrm{e}}$ \\ ${ }^{a}$ Department of Medicine, Division of Physiology, University of \\ Fribourg, Chemin Du Musée 5, 1700 Fribourg, Switzerland \\ ${ }^{b}$ Division of Geriatric Psychiatry, University Hospitals of Geneva, \\ Belle-Idée, 1225 Geneva and Division of Old Age Psychiatry, Univer- \\ sity of Lausanne, 1008 Prilly, Switzerland \\ 'Institute of Parasitology, University of Bern, 3012, Bern, Switzerland \\ ${ }^{d}$ Institut Universitaire de Cardiologie et de Pneumologie, Hopital Laval, \\ Quebec, Canada \\ 'Institute of Animal Sciences, ETH Zurich, Schorenstrasse 16, Zurich \\ 8603 Schwerzenbach, Switzerland
}

\begin{abstract}
To determine whether Toxoplasma gondii infection could modify biological phenomena associated with brain ischemia, we investigated the effect of permanent middle cerebral artery occlusion (MCAO) on neuronal survival, inflammation and redox state in chronically infected mice. Infected animals showed a $\mathbf{4 0} \%$ to $50 \%$ decrease of infarct size compared with non-infected littermates 1, 4 and 14 days after MCAO. The resistance of infected mice may be associated with increased basal levels of anti-inflammatory cytokines and/or a marked reduction of the MCAO-related brain induction of two pro-inflammatory cytokines, tumor necrosis factor-alpha and interferon-gamma (IFN $\gamma$ ). In addition, potential anti-inflammatory/neuroprotective factors such as nerve growth factor, suppressor of cytokine signaling-3, superoxide dismutase activity, uncoupling protein-2 and glutathione (GSH) were upregulated in the brain of infected mice. Consistent with a role of GSH in central cytokine regulation, GSH depletion by diethyl maleate inhibited Toxoplasma gondii lesion resistance by increasing the proinflammatory cytokine IFN $\gamma$ brain levels. Overall, these findings indicate that chronic toxoplasmosis decisively influences both the inflammatory molecular events and outcome of cerebral ischemia.
\end{abstract}

Key words: toxoplasmosis, cerebral ischemia, cytokines, redox factors, rodent.

One of the possible biological consequences of infection is a change of the redox status in both CNS and peripheral

\footnotetext{
${ }^{1}$ Equal first authors.

*Corresponding author. Tel: +41-79-501-52-83; fax: +41-26-300-97-34

E-mail address: denis.arsenijevic@unifr.ch (D. Arsenijevic).

Abbreviations: cDNA, complementary DNA; DEM, diethyl maleate; GAPDH, glyceraldehyde 3-phosphate dehydrogenase; GSH, glutathione; IFN $\gamma$, interferon-gamma; IL-2, interleukin-2; IL-10, interleukin-10; LPS, lipopolysaccharide; MCAO, middle cerebral artery occlusion; NGF, nerve growth factor; SOCS, suppressor of cytokine signaling; SOCS-3, suppressor of cytokine signaling-3; SOD, superoxide dismutase; TNF $\alpha$, tumor necrosis factor-alpha; TUNEL, terminal deoxynucleotidyl transferase biotin-dUTP nick end labeling; UCP2, uncoupling protein-2.
}

tissues (Arsenijevic et al., 2001). Although both animal models and clinical studies showed that infections promote neuronal death following cerebral ischemic injury (Sacco, 2001; Emsley and Tyrrell, 2002), activation of the immune system can also result in neuroprotection (Bordet et al., 2000). In fact, the effect of infection on ischemic damage may largely depend on the regulation of reactive oxygen species by pro-inflammatory and anti-inflammatory cytokines as well as by the main antioxidant state regulators, namely superoxide dismutase (SOD) (Guegan et al., 1998; Murakami et al., 1998), glutathione (GSH) (Nicholls and Budd, 2000; Schulz et al., 2000; Droge, 2002), uncoupling protein-2 (UCP2) (Arsenijevic et al., 2000b; Mattiasson et al., 2003) and nerve growth factor (NGF) (Brodie, 1996; Guegan et al., 1999; Villoslada et al., 2000). In addition, the newly described suppressor of cytokine signaling (SOCS) proteins are induced in peripheral and central models of inflammation (Lebel et al., 2000; Bates et al., 2001; Larsen and Ropke, 2002; Wang and Campbell, 2002; Huang et al., 2003; Park et al., 2003; Jo et al., 2005). SOCS possibly interact with cellular redox determinants (Park et al., 2003) and transgenic SOCS expression has been shown to inhibit inflammation and apoptosis following lipopolysaccharide (LPS) injection (Jo et al., 2005).

Chronic murine toxoplasmosis may be of particular interest in the study of infection-related effects on brain ischemia since it is associated with a tissue-specific regulation of the oxidative state (Arsenijevic et al., 2001) as well as activation of pro-inflammatory cytokines such as tumor necrosis factor-alpha (TNF $\alpha$ ), interferon-gamma (IFN $\gamma$ ) and interleukin-2 (IL-2), but also anti-inflammatory cytokines such as interleukin-10 (IL-10) (Arsenijevic et al., 1997, 1998). Some of these cytokines are known to enhance neurodegeneration following ischemia (Arsenijevic et al., 2006). In order to determine how chronic infection influences the main biological phenomena associated with acute cerebral ischemia, the present study explores the impact of chronic Toxoplasma gondii infection on brain ischemic injury and inflammatory/antioxidant processes induced by permanent middle cerebral artery occlusion (MCAO).

\section{EXPERIMENTAL PROCEDURES}

All procedures were approved by the Veterinary Office of the Canton of Zurich Health Directorate and the Veterinary Office of Geneva in accordance with the Swiss Animal Care Guidelines. All efforts were made to minimize the number of animals used in this study and every effort was taken to reduce any suffering. 


\section{Mice and diets}

Male Swiss Webster mice of 4 months of age from Charles River Laboratories (Wilmington, MA, USA) were used. Mice were chronically infected by i.p. injection of 10 cysts of Toxoplasma gondii (Me49 strain obtained from Dr A. Hemphill, University of Bern, Switzerland) (Arsenijevic et al., 1997). Less than $5 \%$ of mice died due to infection during weeks 2 and 3 . After this time point all infected mice survived. Acute infection with Toxoplasma gondii results in anorexia and body weight loss (Arsenijevic et al., 1997). We followed infected mice body weight and food intake 7 days before infection and up to 28 days (chronic phase) after infection $(n=10)$. In the chronic phase of infection, some of these mice may show a partial weight regain $(50 \%)$ or no weight regain $(50 \%)$ (Arsenijevic et al., 1997). For all experiments, we used only the latter type of mice since these animals had higher basal brain cytokine levels and were expected to maximally respond to a new inflammation (Arsenijevic et al., 1998). A group of non-infected mice $(n=18)$ was chronically underfed to mimic the food intake level of infected mice from days 1-28. This group was used to determine: 1) if the reduced food intake of the infected mice may influence basal brain GSH levels $(n=6) ; 2)$ the effect of underfeeding on brain GSH levels after MCAO $(n=6)$ and 3 ) the effect of underfeeding on ischemic lesion size $(n=6)$. All mice were individually weighed and food intake was measured daily. For the MCAO study, infected and non-infected mice with and without MCAO ( $n=18$ mice per group) were monitored daily from 7 days prior to and up until 3 days after operation. Daily food intake ( $\mathrm{g} / \mathrm{mouse} / \mathrm{day})$ and body weight changes after MCAO were measured, and food intake changes after MCAO were calculated as a percentage of pre-ischemia average food intake for each mouse group.

\section{Histology of infected brains compared with non-infected controls}

Histological analysis was performed in infected (28 days following infection) $(n=4)$ and non-infected control brains $(n=4)$ prior to MCAO. Brain slices $(20 \mu \mathrm{m})$ were stained with hematoxylin and eosin for histological identification of Toxoplasma gondii cysts and infiltrating immune cells (Frenkel and Escajadillo, 1987; Arsenijevic et al., 2007a). Detection of apoptosis in the brain of chronically infected mice was made using terminal deoxynucleotidyl transferase biotin-dUTP nick end labeling (TUNEL) labeling as previously described (de Bilbao et al., 2000). The suppressor of cytokine signaling-3 (SOCS-3) mRNA expression was determined by in situ hybridization in the brains of these mice ( $n=6$ per group). Riboprobe preparation and in situ hybridization histochemistry were kindly performed by Dr S. Rivest (Laval University, Canada). The rat SOCS-3 complementary DNA (CDNA) fragment that was initially inserted in a pEF-FLAG-1 vector (provided by Dr. Doug Hilton, The Walter and Eliza Hall Institute of Medical Research, Melbourne, Australia) was extracted with $X b a l$ and reinserted into a pCRII (Invitrogen, Carlsbad, CA, USA). The new construct was then linearized with Xhol. 35S-UTP was used to label the probe (for the complete in situ hybridization protocol conditions see reference by Lebel et al., 2000).

\section{Induction of permanent focal cerebral ischemia and volume of the infarct}

Mice were operated 28 days after infection, when their body weight and food intake had stabilized (Arsenijevic et al., 1998). We performed permanent MCAO in infected and non-infected control mice ( $n=6$ for each group and post-MCAO time) as described in details elsewhere (de Bilbao et al., 2000). All mice survived and showed infarction after MCAO. One day, 4 days and 14 days later, the animals were perfused through the ascending aorta with a solution of paraformaldehyde $4 \%$ in phosphate-buffered saline
(PBS, pH 7.35). Brains were removed and processed for paraffin embedding. Sections $(7 \mu \mathrm{m})$ of the whole infarct area were cut on slides pretreated with 3-aminopropyltriethoxy-silane (Sigma, MO, USA), counterstained with Cresyl Violet for the histological identification of the nuclear boundaries and peri-infarct areas and mounted in Eukitt. For each animal, quantification of the infarcted area was performed on the Cresyl Violet-stained sections at five representative levels throughout the rostro-caudal extent of the lesion (A 0.26, $-0.22,-0.40,-0.70$ and $-1.2-4 \mathrm{~mm}$ relative to Bregma) (Franklin and Paxinos, 1997). The rostro-caudal extent of the infarct was the same in both groups of mice. The infarcted area of each section was calculated by the subtraction of healthy tissue areas of the contralateral to the ipsilateral side of the section in order to compensate for the effect of brain edema (Guegan et al., 1998) using a computer-assisted image analyzing system (Software Morphometry, Samba 2005 TITN, Alcatel). Volumes of infarct $\left(\mathrm{mm}^{3}\right)$ were calculated for each animal after integration of areas with the distance between each level (de Bilbao et al., 2000).

To evaluate whether local alterations in cerebral vascular anatomy contribute to different susceptibility to injury in infected mice, an additional series of five non-infected and five infected mice were killed on day 1 after ischemia. Cerebral vasculature was studied in non-infected and infected mice (non-operated and on day 1 after ischemia) after intracardial perfusion of a mixture of an equal proportion of gelatinous water $(5 \%)$ and China ink (Sennelier, France) warmed at $40{ }^{\circ} \mathrm{C}(1 \mathrm{ml})$. Brains were removed and immersed for $24 \mathrm{~h}$ in $4 \%$ paraformaldehyde at $4{ }^{\circ} \mathrm{C}$ (Chen et al., 2005). Cerebral vasculature was observed with a Zeiss stereo zoom microscope. The absence of cerebral blood flow in the infarct area was assessed visually and by transcranial measurements of cerebral blood flow that were made using laser Doppler flowmetry (Oxford Optronix Ltd., UK) just before and after MCAO. Animals were placed under a stereotactic head frame and then a fine needle probe (MNP110XP, $0.48 \mathrm{~mm}$ diameter) was lowered onto the temporal bone surface $0.5-1 \mathrm{~mm}$ dorsal to the opening giving access to the MCA and wetted with a small amount of physiological saline.

\section{Physiological parameters}

Physiological parameters including arterial blood pressure (Kent mouse tail blood pressure system RTBP2000, Kent Scientific Corporation, Torrington, USA), plasma glucose (using Roche Glucotrend Active, Rotkreuz, Switzerland) and hematocrit were measured daily ( $n=5$ for each type of mice) before MCAO and on day 1 and day 4 after injury. During surgery, mice were placed on a warm mat and rectal temperature was measured. During the operation, all mice had a body temperature of $38^{\circ} \mathrm{C}$.

\section{Northern blot for UCP2 mRNA}

Infected and non-infected mice subjected or not to ischemia (1 day post-MCAO) ( $n=6$ mice per group) were anesthetized i.p. with xylazine $(20 \mathrm{mg} / \mathrm{kg}) / \mathrm{ketamine}(100 \mathrm{mg} / \mathrm{kg})$ in $0.9 \% \mathrm{NaCl}(100 \mu \mathrm{l} /$ $10 \mathrm{~g}$ body weight). They were intracardially perfused without delay with ice-cold isotonic saline. At the end of the perfusion the whole brains were quickly dissected out and frozen. Total RNA was prepared as described before (Arsenijevic et al., 1997). Northern blot analyses were performed using the mouse UCP2 or glyceraldehyde 3-phosphate dehydrogenase (GAPDH) cDNA labeled with ${ }^{32} \mathrm{P}$ under standard conditions. A similar amount of total RNA $(20 \mu \mathrm{g})$ was used in every lane.

\section{Cytokines and NGF levels in brain}

We measured TNF $\alpha$, IFN $\gamma, \mathrm{IL}-10, \mathrm{IL}-2$ and NGF in the brain of infected and non-infected mice subjected or not to ischemia (1 day post-MCAO; $n=6$ mice per group). Brains were analyzed 1 day 
after ischemia since it is well established that cytokines return to basal levels after this time point (Guegan et al., 1998). They were aseptically removed, immediately placed in dry ice and then put in CHAPS solution and homogenized (Arsenijevic et al., 2000a). The supernatant was collected and frozen at $-20{ }^{\circ} \mathrm{C}$. TNF $\alpha$, IFN $\gamma$, $\mathrm{IL}-10$, and IL-2 were measured by using immunoassay kits from Amersham (Switzerland) (Arsenijevic et al., 2006). An immunoassay kit was also used to determine NGF (Catalys, Switzerland) (Arsenijevic et al., 2006).

\section{SOD activity}

We investigated SOD activity using a biochemical assay (1 day post-MCAO; $n=6$ mice per group) (Ewing and Janero, 1995). Brains were homogenized in phosphate-buffered saline and frozen immediately in liquid nitrogen. Aliquots of brain supernatants were processed as previously described (Ewing and Janero, 1995). Brain supernatants were added $(25 \mu \mathrm{l})$ to a $125 \mu$ l solution containing $50 \mathrm{mM}$ phosphate buffer ( $\mathrm{pH} 7.4,0.1 \mathrm{mM}$ EDTA, $50 \mu \mathrm{M}$ NBT, $78 \mu \mathrm{M}$ NADH). To start the reaction, $25 \mu \mathrm{l}$ of $3.3 \mu \mathrm{M}$ PMS phenazine methosulfate (Sigma) (final concentration) was added and the absorbance at $560 \mathrm{~nm}$ was measured continuously using a microplate reader (DynaTech MR5000). The readings were every minute for $10 \mathrm{~min}$. The first $5 \mathrm{~min}$ were used to determine the rate of superoxide production by the samples.

\section{GSH levels}

Tissues were collected from infected $(1,3,7,14$ and 28 days post-infection) and non-infected control mice ( $n=6$ mice per group). The consequences of MCAO for brain GSH levels were also determined in both types of mice 1 day post-ischemia $(n=6$ for each group). Tissues were homogenized in phosphate buffer (50 mM, pH 7.4). Total GSH levels were measured using a method based on the formation of a chromophoric product resulting from the reaction of 5,5' -dithiobis-(2-nitrobenzoic acid) (DTNB, Sigma) and GSH (Sigma) (de Bilbao et al., 2004). The absorbance was immediately measured at $412 \mathrm{~nm}$. GSH contents were calculated by using a calibration curve established with standard samples.

To test whether elevated brain GSH levels in infected mice 1) were involved in the lack of cytokine induction 1 day after MCAO and 2) may influence lesion size response after ischemia, GSH was depleted by a s.c. injection of diethyl maleate (DEM) (24 $\mu \mathrm{l} / 30 \mathrm{~g}$ body weight and was made up to $300 \mu \mathrm{l}$ with saline) (Pileblad and Magnusson, 1990). To determine if DEM depleted brain GSH, non-infected $(n=3)$ and infected mice $(n=3)$ were treated with DEM and killed $2 \mathrm{~h}$ later and $\mathrm{GSH}$ in brain was measured as described above. To determine whether GSH depletion may alter TNF $\alpha$ and IFN $\gamma$ levels 1 day after MCAO, infected $(n=4)$ and non-infected mice $(n=4)$ were treated with DEM, underwent MCAO $2 \mathrm{~h}$ later and were killed 1 day post-ischemia. Estimates of brain cytokine levels were obtained as described above. For all experiments, mice treated with saline were used as controls for the DEM groups.

Brains of 28-day infected mice (see Histology section) were stained for GSH with the fluorescent histochemical dye phthaldialdehyde $(10 \mathrm{mM})$ and then processed for microglia immunohistochemistry using the anti-lba-1 antibody $(1 \mathrm{mg} / \mathrm{ml}$, from $\mathrm{Dr}$. Y. Imai, National Center of Neurology and Psychiatry, Japan) which was detected by the fluorescent goat-anti-rabbit immunoglobulin Alexa Fluor 568 (Molecular Probes) (de Bilbao et al., 2004). Since we have previously shown that chronic toxoplasmosis results in an increased brain expression of UCP2 mRNA which is specific for microglia associated with inflammatory loci (Arsenijevic et al., 2007), we also explored whether there was an association between GSH and UCP2 in this cell type. Mounted brain sections were immunostained for $\mathrm{GSH}$ using rabbit polyclonal anti-GSH (1/10 dilution provided by Prof. Ottersen, University of Oslo, Nor-
Table 1. Physiological parameters before and after MCAO in noninfected and infected mice

\begin{tabular}{lccr}
\hline Group and treatment & $\begin{array}{l}\text { 1 Day } \\
\text { before MCAO }\end{array}$ & $\begin{array}{l}\text { D1 after } \\
\text { MCAO }\end{array}$ & $\begin{array}{l}\text { D4 after } \\
\text { MCAO }\end{array}$ \\
\hline $\begin{array}{l}\text { Hematocrit (\%) } \\
\quad \text { Non-infected }\end{array}$ & $42 \pm 4$ & $44 \pm 5$ & $45 \pm 5$ \\
$\quad$ Infected & $48 \pm 4$ & $50 \pm 4$ & $51 \pm 4$ \\
Plasma glucose (mmol/L) & & & \\
$\quad$ Non-infected & $8.2 \pm 0.2$ & $7.9 \pm 0.3$ & $8.1 \pm 5$ \\
$\quad$ Infected & $7.7 \pm 0.3$ & $7.6 \pm 0.2$ & $7.8 \pm 4$ \\
$\begin{array}{l}\text { Arterial pressure (mm Hg) } \\
\quad \text { Non-infected }\end{array}$ & $94 \pm 8$ & $96 \pm 8$ & $95 \pm 5$ \\
$\quad$ Infected & $105 \pm 12$ & $98 \pm 9$ & $101 \pm 6$ \\
\hline
\end{tabular}

Data are means \pm S.E.M. of 5 animals per group. See text for details.

way) which was revealed by $A B C$ kit peroxidase and subsequently processed for in situ hybridization using a rat UCP2 probe (de Bilbao et al., 2004).

\section{Data analyses}

All data are presented as means \pm S.E. Statistical analyses were performed using Kruskal-Wallis non-parametric test. $P$ values of less than 0.05 were considered significant.

\section{RESULTS}

\section{Physiological parameters before and after MCAO}

Arterial pressure, plasma glucose and hematocrit levels before and after MCAO on day 1 and day 4 were not significantly different between non-infected and infected mice at a given time point as shown in Table 1. After MCAO, both non-infected and infected mice showed an absence of cerebral blood flow in the infarct area.

\section{Brain histology and SOCS-3 mRNA induction in infected mice}

Unlike non-infected mice, the brains of the infected mice showed many randomly located inflammatory loci (including neutrophils, macrophages/monocytes and lymphocytes) 28 days after infection. These loci were not colocalized with intact Toxoplasma gondii cysts (Fig. 1A, B) and also occurred around blood vessels, but not within the vessels' walls (Fig. 1C). There was no evidence of neuronal apoptosis as determined by TUNEL labeling in these mice (data not shown). In situ hybridization showed SOCS-3 basal expression mainly in the hypothalamic region (Fig. 1D) (Lebel et al., 2000). Following infection, SOCS-3 mRNA labeling was randomly induced throughout the cerebral cortex as well as in areas associated with brain immune cell infiltration and blood vessels (Fig. 1D). This expression was associated with neurons, microglia and infiltrating phagocytes as previously described (data not shown) (Lebel et al., 2000).

\section{Ischemic brain injury is reduced in Toxoplasma gondii infected mice}

One day, 4 days and 14 days after MCAO, infarct volume was decreased by $42 \%, 50 \%$ and $48 \%$ respectively in 

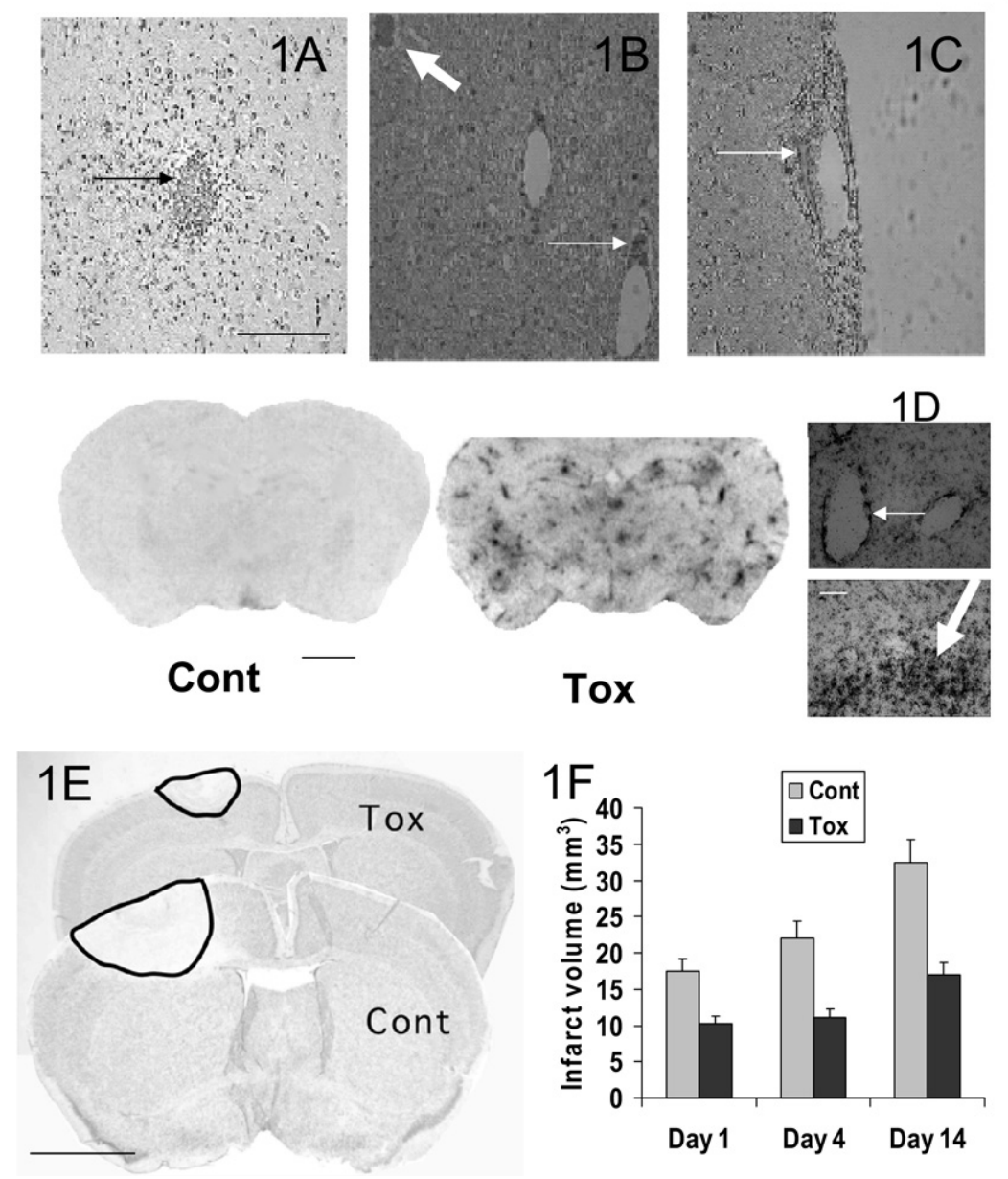

Fig. 1. Brain histology, in situ hybridization for SOCS-3 mRNA expression and brain infarct size in Toxoplasma gondii infected mice. (A-C) Coronal cross-sections of a Toxoplasma gondii-infected (for 28 days) mouse brain stained with hematoxylin and eosin (scale bar $=15 \mu \mathrm{m}$ ). Note that infection resulted in inflammatory loci found in brain tissue (A) (thin black arrow) and in association with blood vessels (B, C) (thin black arrows). Note also that the presence of Toxoplasma cysts was not associated with inflammatory loci (B, thick arrow). (D) Representative in situ hybridization for SOCS-3 mRNA in non-infected control (Cont) and infected mice (Tox) brains (scale bar $=120 \mu \mathrm{m}$ ). SOCS-3 mRNA basal expression was found in particular in hypothalamic region. Twenty-eight days following infection, SOCS-3 mRNA expression was randomly located and induced throughout the brain of infected mice in particular in the cortical area (Tox) ( $n=4$ for each group). The right column shows a higher magnification of selected areas specific for SOCS-3 mRNA expression in infected brains. SOCS-3 mRNA was associated with microglia/infiltrated immune cells (thick arrow) and blood vessels (thin arrow). Cells are visualized with Thionin staining and SOCS-3 silver grains are black (scale bars=15 $\mu \mathrm{m}$ ). (E, F) Effect of Toxoplasma gondii infection on infarct size. (E) Representative coronal sections showing ischemic lesion size 4 days after MCAO in control (Cont MCAO) and chronically infected mice (Tox MCAO). Sections were stained with Cresyl Violet. The surrounded areas denote the size of the ischemic area (scale bars $=120 \mu \mathrm{m})$. (F) Infarct brain volumes were reduced in infected mice (Tox) at 1, 4 and 14 days after MCAO compared with non-infected mice (Cont).

Toxoplasma gondii infected mice when compared with non-infected control mice $(P<0.01)$ (Fig. 1E, F), suggesting that chronic infection with Toxoplasma gondii may protect neocortical areas from ischemic damage.

\section{Transient hyperphagia occurs early in Toxoplasma gondii-infected mice in response to MCAO}

On the day of lesion, MCAO resulted in a significant reduction of food intake in both infected and non-infected control mice when compared with their pre-MCAO basal food intakes $(-26 \pm 0.5 \%$ and $-39 \pm 0.7 \%$ respectively, $n=18, P<0.01)$. The day after ischemia, both non-infected and infected mice started to regain appetite. From this time point, infected mice increased food intake more rapidly than the non-infected group $(-3 \pm 0.2 \%$ and $-28 \pm 2 \%$, respectively, $n=18, P<0.01)$. Infected mice showed significantly enhanced hyperphagia on days 2 and 3 postischemia compared with their non-operated controls $(28 \pm 1.2 \%$ and $1 \pm 0.2 \%$ respectively, $n=18, P<0.01$ ). Body weight loss induced by ischemia followed a similar temporal pattern to that of food intake indicating that Toxoplasma gondii-infected mice had attenuated negative energy balance in response to MCAO.

\section{Brain specific alterations in GSH levels due to infection}

There was a $45 \%$ decrease in brain GSH levels on day 7 postinfection when compared with non-infected control 

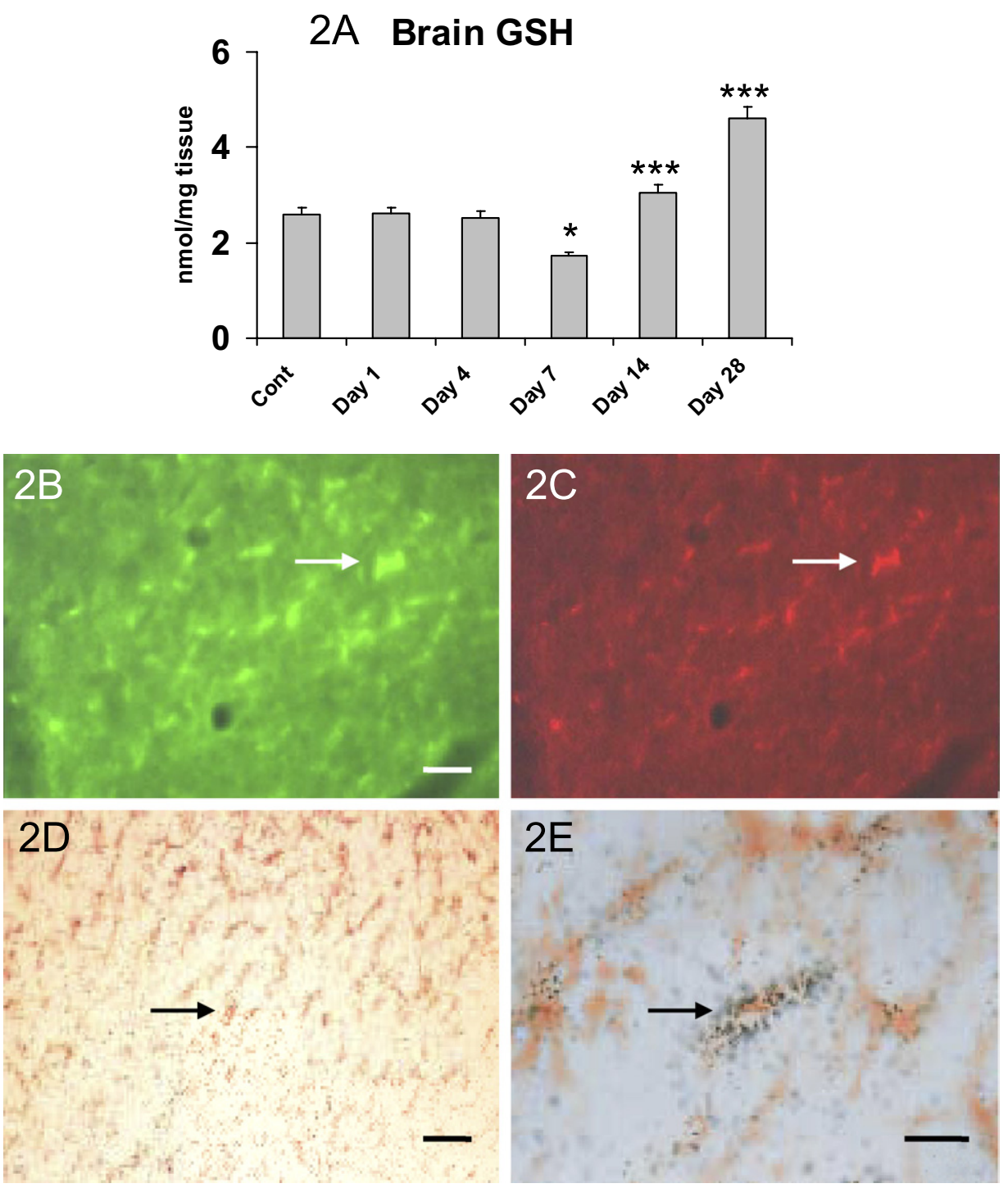

Fig. 2. Changes in brain GSH levels from day 1 to day 28 following murine Toxoplasma gondii infection. (A) Toxoplasmosis resulted in a slight reduction in brain GSH levels on day 7 . From day 14 to day 28 after infection, GSH was significantly increased in the brain of infected mice compared with non-infected control mice (Cont). Values (nmol/mg tissue) are presented as mean \pm S.E. $\left({ }^{*} P<0.05\right.$, ${ }^{* *} P<0.001$, comparison to saline control). Each group represents six mice. (B) GSH (fluorescent staining, white arrow) is specifically increased in microglia in infected mice (red, white arrow) (C). Only microglia cells that have increased UCP2 mRNA (E, black arrow) show an increase in GSH (immunohistochemical detection, orange, black arrow) (D). Scale bars $=15 \mu \mathrm{m}(B, C, D) ; 7.5 \mu \mathrm{m}(E)$. For interpretation of the references to color in this figure legend, the reader is referred to the Web version of this article.

mice $(P<0.05)$. On day 14 , as mice started to regain appetite, there was a progressive increase in brain $\mathrm{GSH}$ levels in infected mice $(P<0.001)$ up to 28 days after infection $(P<0.001)$ (Fig. 2A). The increase in $\mathrm{GSH}$ in the brains of 28-day infected mice was associated with a specific increase in microglia (Fig. $2 \mathrm{~B}, \mathrm{C}$ ); only microglia with elevated UCP2 mRNA levels showed GSH labeling (Fig. $2 \mathrm{D}, \mathrm{E})$. In non-infected control mice, MCAO resulted in a $80 \%$ decrease of brain GSH levels (from $0.52 \pm$ $0.02 \mathrm{nmol} / \mathrm{mg}$ tissue to $2.60 \pm 0.18 \mathrm{nmol} / \mathrm{mg}$ tissue) $(P<0.001)$ (Fig. 3A). Interestingly, this decrease due to ischemia was only $11 \%$ in infected animals (from $4.60 \pm$ $0.80-4.11 \pm 0.31 \mathrm{nmol} / \mathrm{mg}$ tissue) $(P<0.01)$. In addition, $\mathrm{GSH}$ brain content in infected animals having undergone
MCAO was significantly higher compared with non-infected MCAO animals $(P<0.001)$ (Fig. 3A). Chronically underfed non-infected mice did not show altered brain

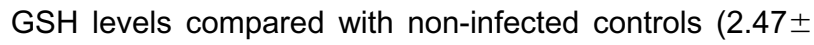
0.19 versus $2.60 \pm 0.07 \mathrm{nmol} / \mathrm{mg}$ tissue) (Fig. $3 \mathrm{~A}$ ) suggesting that anorexia does not explain the increased brain GSH levels in infected mice. Although 1 day after ischemia, GSH levels were reduced in the chronically underfed noninfected mice, this decrease was significantly less pronounced compared with the non-infected control group $(P<0.01)$ (Fig. 3A). This was associated with a reduced infarct size in the chronically underfed group compared with the non-infected control group $\left(15.0 \pm 0.9 \mathrm{~mm}^{3}\right.$ and $19.3 \pm 1.1 \mathrm{~mm}^{3}$, respectively, $n=6$ mice, $\left.P<0.05\right)$. Al- 

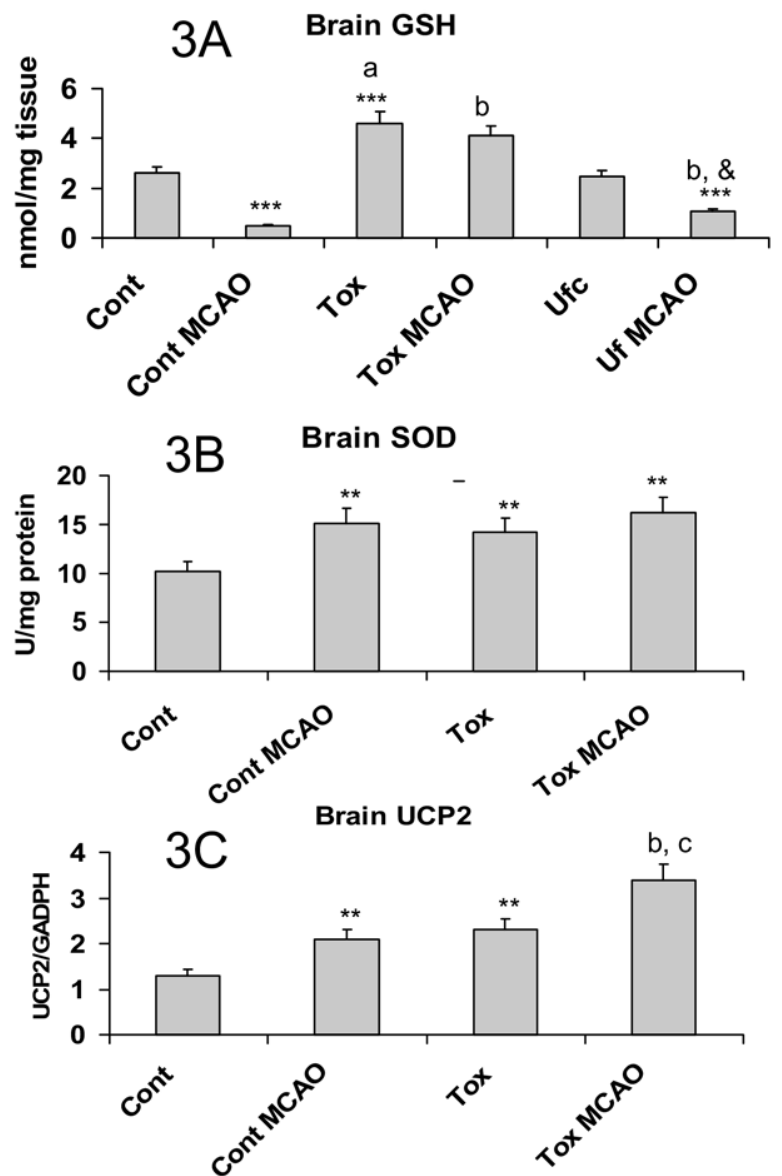

Fig. 3. Brain $\mathrm{GSH}$, brain SOD activity and brain UCP2 mRNA expression. (A) One day after MCAO, we observed a reduction in brain GSH levels in non-infected mice (Cont MCAO) compared with their nonoperated controls (Cont). After MCAO, brain levels of GSH in infected mice were markedly elevated compared with non-infected animals (Cont MCAO). Underfeeding (Ufc) results in no change in brain GSH levels compared with control mice (Cont). One day after MCAO, GSH level in underfed mice (Ufc MCAO) was reduced, however this reduction was less than that found in Cont MCAO mice. (B) Brain SOD activity was increased during chronic infection (Tox) when compared with non-infected animals (Cont). One day post-MCAO, SOD activities were similarly increased in both groups compared with non-infected controls (Cont). (C) Brain UCP2 mRNA expression was increased following infection (Tox) compared with non-infected controls (Cont). MCAO increased brain UCP2 mRNA levels in both infected and noninfected mice, but levels were higher in the former group. Values are presented as mean $\pm S$.E. for the various groups. Each group represents six mice. * Indicates the statistical comparison with non-infected controls (Cont), ${ }^{a}$ indicates the statistical comparison between Tox and Ufc mice, ${ }^{b}$ indicates the statistical comparison between Tox MCAO and Cont MCAO mice, ${ }^{\mathrm{C}}$ indicates the statistical comparison between Tox and Tox MCAO mice, \& indicates comparison between Cont MCAO and UfC MCAO $\left({ }^{*} P<0.05, \quad{ }^{* * *} P<0.001, \quad{ }^{* *} P<0.01\right.$, ${ }^{* * *} P<0.001,{ }^{\mathrm{a}} P<0.001,{ }^{\mathrm{b}} P<0.001,{ }^{\mathrm{c}} P<0.05$, \& $P<0.01$ ).

though a contributing effect cannot be excluded, the underfeeding effect on reduced lesion size could not totally explain the much greater reduction of infarct size observed in the infected mice $\left(10.2 \pm 0.4 \mathrm{~mm}^{3}\right)$ (Fig. 1F) $(P<0.05)$.

\section{Infection increases brain SOD activity}

SOD activity (Fig. 3B) was higher in the brains of infected mice (14.2 \pm 1.2 units $/ \mathrm{mg}$ protein) compared with non-infected mice $(10.2 \pm 0.8$ units $/ \mathrm{mg}$ protein) $(P<0.01)$. This difference did not persist 1 day after MCAO (Fig. 3B) as SOD activities were similarly increased in both groups $(17.2 \pm 1.5$ and $15.1 \pm 1.1$ units/mg protein respectively).

\section{Upregulation of brain UCP2 mRNA levels in infected mice after ischemia}

Toxoplasmosis resulted in a $76 \%$ increase in brain UCP2/ GAPDH mRNA ratio compared with non-infected mice $(2.3 \pm 0.2$ versus $1.3 \pm 0.1)(P<0.01)$ (Fig. $3 C$ ). One day post$\mathrm{MCAO}$, there was a $62 \%$ increase in UCP2/GADPH mRNA ratio in infected mice compared with MCAO non-infected mice $(3.4 \pm 0.2$ versus $2.1 \pm 0.2)(P<0.001)$ (Fig. $3 C)$.

\section{Infection does not result in enhanced cytokine levels after MCAO}

Basal levels of proinflammatory cytokines (TNF $\alpha$, IL-2, IFN $\gamma$ ) were increased in Toxoplasma gondii infected mice on day 28 postinfection compared with non-infected controls $(P<0.001)$ (Table 2). One day post-MCAO, infected mice had higher TNF $\alpha$, IL-2 and IFN $\gamma$ levels compared with MCAO non-infected animals $(P<0.001)$. However, these higher levels did not significantly differ from those observed in infected mice not subjected to ischemia. This sharply contrasts with the results obtained in non-infected mice which showed a marked induction of cytokine levels 1 day post-MCAO compared with non-operated animals. Infected mice also had significantly higher brain levels of IL-10 and NGF compared with non-infected control mice $(P<0.001)$ (Table 2). NGF and IL-10 significantly increased in non-infected mice that underwent MCAO $(P<0.001)$; this induction was not observed in infected mice suggesting an attenuated immune response in the brains of infected mice (Table 2). Following MCAO, NGF levels in infected animals were doubled compared with non-infected controls $(P<0.001)$. This was not the case for IL-10 suggesting that NGF may be a more important antiinflammatory agent in infected mice.

Table 2. Basal and one day post-MCAO levels of brain $\operatorname{TNF} \alpha$, IFN $\gamma$, IL-2, IL-10 and NGF in non-infected and infected mice

\begin{tabular}{|c|c|c|c|c|}
\hline & Cont & Cont MCAO & Tox & Tox MCAO \\
\hline $\mathrm{TNF} \alpha \mathrm{pg} / \mathrm{ml}$ & $100 \pm 4$ & $800 \pm 12^{* * *}$ & $993 \pm 51^{* * *}$ & $1093 \pm 50^{a}$ \\
\hline $\mathrm{IFN} \gamma \mathrm{pg} / \mathrm{ml}$ & $25 \pm 2$ & $175 \pm 4^{* * *}$ & $330 \pm 8^{* * *}$ & $358 \pm 9^{a}$ \\
\hline $\mathrm{IL}-2 \mathrm{pg} / \mathrm{ml}$ & $44 \pm 2$ & $750 \pm 23^{* * *}$ & $1622 \pm 64^{* * *}$ & $1804 \pm 61^{a}$ \\
\hline IL-10 pg/ml & $24 \pm 2$ & $492 \pm 38^{* * *}$ & $504 \pm 40^{* * *}$ & $560 \pm 19$ \\
\hline NGF pg/ml & $40 \pm 3$ & $300 \pm 12^{* * *}$ & $600 \pm 22^{* * *}$ & $624 \pm 20^{a}$ \\
\hline
\end{tabular}

Values (pg/ml tissue) are presented as mean \pm S.E.

* Indicates statistical comparison with non-infected animals (Cont) $\left({ }^{* * *} P<0.001\right)$. Each group included six mice. See text for details. ${ }^{a}$ Indicates statistical comparison between Tox MCAO and Cont MCAO mice ( $\left.{ }^{a} P<0.001\right)$. Each group included six mice. See text for details. 

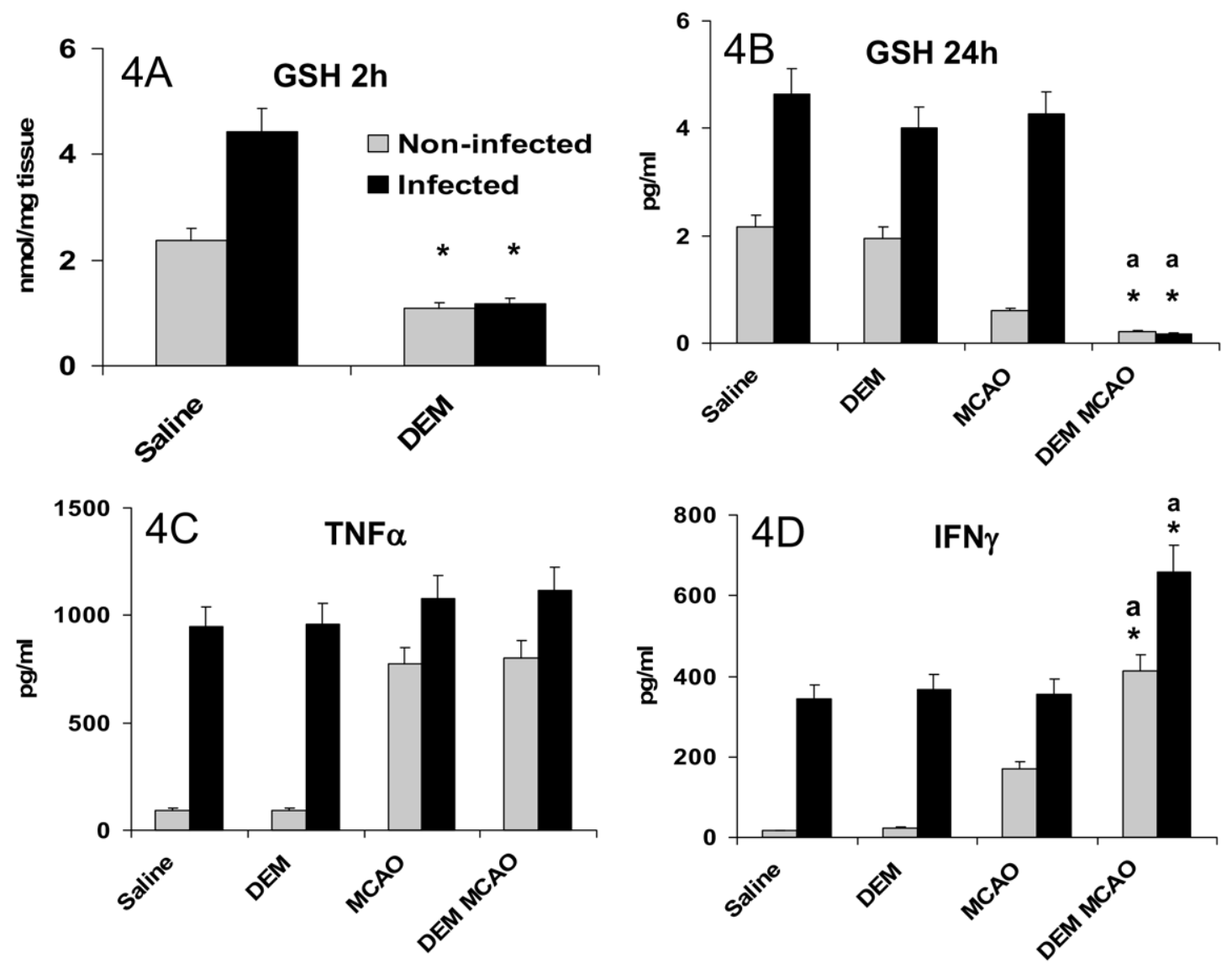

Fig. 4. GSH, TNF $\alpha$ and IFN $\gamma$ were measured in non-infected and infected mice after ischemia; $2 \mathrm{~h}$ prior to MCAO, mice were treated with DEM (or saline). (A) DEM significantly reduced brain GSH in non-infected and infected mice $2 \mathrm{~h}$ after treatment. (B) Twenty-four hours after ischemia, DEM significantly reduced brain GSH levels in infected and non-infected mice. Note that, consistent with the known transitory effect of DEM on GSH levels (Gupta et al., 2000), GSH returned to basal levels $24 \mathrm{~h}$ after DEM treatment in the absence of ischemic damage in both infected and non-infected mice. (C, D) DEM did not significantly alter brain TNF $\alpha$ (C) but significantly increased brain IFN $\gamma$ levels (D) $24 \mathrm{~h}$ after ischemia. Data are means \pm S.E. of three to five animals per group. ${ }^{*} P<0.001$, comparison with saline controls; ${ }^{a} P<0.001$, comparison with MCAO controls.

Depletion of brain GSH by DEM reversed neuroprotection by increasing lesion size and central IFN $\gamma$ levels after MCAO in infected mice.

Brain GSH levels in both non-infected and infected mice were markedly decreased $2 \mathrm{~h}$ after an s.c. injection of DEM as seen in Fig. 4A. One day after ischemia (Fig. 4B), brain GSH levels were further reduced by DEM when compared with non-treated MCAO groups. This reduction was associated with an increased lesion size in infected mice when compared with infected mice not treated with DEM $\left(22.2 \pm 1.7 \mathrm{~mm}^{3}\right.$ versus $12.8 \pm 0.5 \mathrm{~mm}^{3}, n=6$ per group, $P<0.01)$. Non-infected mice also showed an increase in lesion size when treated with DEM (15.8 \pm $1.5 \mathrm{~mm}^{3}$ for saline versus $20.3 \pm 1.0 \mathrm{~mm}^{3}$ for DEM, $n=6$ per group, $P<0.05)$. After ischemia, DEM treatment resulted in induction of central IFN $\gamma$ levels but not TNF $\alpha$ in both types of mice (Fig. 4C, D). Note that, consistent with the known transitory effect of DEM on GSH levels (Gupta et al., 2000), GSH returned to basal levels $24 \mathrm{~h}$ after DEM treatment in the absence of ischemic damage in both infected and non-infected mice (Fig. 4C, D).

\section{DISCUSSION}

This study revealed a marked resistance of Toxoplasma gondii-infected mice to acute cerebral ischemia characterized by a marked decrease of infarct size one, and 4 but also 14 days post-MCAO. The reverse effect of DEM on brain infarct size implies that GSH up-regulation may play a pivotal role in the observed ischemic resistance. Our results make it also possible to propose additional biological mechanisms surrounding this phenomenon, such as marked differences in pre- and/or post-ischemic cytokine status as well as pre- and/or post-ischemic GSH, SOCS-3 mRNA and UCP2 mRNA levels in infected compared with non-infected mice.

Following the acute phase of toxoplasmosis, the initially produced pro-inflammatory cytokines will subsequently induce a counter-regulatory anti-inflammatory response (Arsenijevic et al., 1997). During the chronic phase of infection, apart from the role that the adaptive specific immune systems (CD4, CD8 T cell activation) could play, the consequence of a second inflammation caused by 
cerebral ischemia may be determined by the balance between these two antagonistic systems. The basal up-regulation of antioxidant molecules such as GSH, SOD, UCP2, SOCS-3 mRNA and anti-inflammatory cytokines NGF and IL-10 may represent the two first lines of defense against ischemic damage in infected mice. One could postulate that the observed changes in redox status may be a simple epiphenomenon of the underfeeding observed in the chronically infected mice. In fact, it has been shown that underfeeding may result in protection from cerebral injury by modifying redox status (Yu and Mattson, 1999). Our findings show that both the steady increase of brain GSH levels by day 7 to day 28 post-infection as well as the brain resistance to ischemia are specific to Toxoplasma gondii infection and did not depend on energy intake. Actually, although we did find that post-ischemic GSH was partially dependent on energy intake, this component represented only $13 \%$ of the post-ischemic GSH levels of infected mice. We also show that energy intake does influence lesion size, but alone cannot account for the degree of resistance observed in infected animals. A possible causal relationship between redox status and cytokine production has been previously suggested in that increased basal GSH levels and SOD activity may result from high NGF levels (Guegan et al., 1998, 1999; de Bilbao et al., 2004; Arsenijevic et al., 2006). Consistent with their possible role in neuroprotection (Guegan et al., 1999; Mattiasson et al., 2003), the differences in GSH, UCP2 mRNA and NGF levels persisted between infected and non-infected mice after MCAO. In the absence of a specific antibody for brain UCP2, it was not possible to assess the impact of UCP2 mRNA changes on protein levels. However, previous data using UCP2 transgenic and UCP2 KO mice have shown that UCP2 plays a central role in brain neuroprotection following ischemia (Mattiasson et al., 2003; de Bilbao et al., 2004).

An additional molecular mechanism involved in this context may involve the absence of pro-inflammatory cytokine induction observed in infected mice after ischemia. This phenomenon could be partly due to the already elevated basal levels of these cytokines in the brains of these mice (i.e. counter-regulatory mechanisms). Although one could argue that this finding might reflect the presence of a threshold in cytokine levels reached in Toxoplasma-infected mice, this is an unlikely scenario since we have previously demonstrated that an i.p. injection of LPS led to a marked upregulation of pro-inflammatory cytokines in these mice (Arsenijevic et al., 1998). Importantly, infected mice showed feeding behavior concordant with the relative stunting of brain cytokine response after ischemia. In fact, transient hyperphagia started earlier in infected mice compared with non-infected mice after MCAO. This is consistent with the attenuated post-ischemic induction of anorectic cytokines (TNF $\alpha$, IFN $\gamma$ ) in the brain.

In agreement with previous contributions, our data suggest that both SOCS-3 and GSH are plausible candidate molecules for the regulation of secondary inflammatory response and cytokine production in Toxoplasma gondiiinfected mice (Bjorkbaek et al., 1999; Auerhammer and
Melmed, 2001; Park et al., 2003). The absence of proinflammatory cytokine induction could be partly due to the parallel elevation of the SOCS-3 mRNA after infection. The SOCS-3 is a potent inhibitor of cytokine signaling and its transgenic over-expression may inhibit inflammation and associated apoptosis in vivo (Auerhammer and Melmed, 2001; Jo et al., 2005). Accordingly, although infected mice had elevated basal pro-inflammatory cytokine levels (i.e. TNF $\alpha$, IFN $\gamma$ and IL-2) (Eizenberg et al., 1995; Bate et al., 2006; Lee et al., 2006; Yu et al., 2006), there was no evidence of neuronal apoptosis in their brain tissue. A key role for GSH is suggested by the fact that the decreased infarct size in MCAO mice chronically infected is no longer observed when brain GSH levels have been depleted by DEM treatment. This phenomenon was specifically associated with the central up-regulation of pro-inflammatory IFN $\gamma$ but not TNF $\alpha$ in response to MCAO. Previous studies have also shown that DEM may not have a marked effect on TNF induction in response to an inflammatory response (Kang et al., 1999; Wang et al., 1999). Further work is needed to get a better understanding of the complex interactions of molecules regulating the inflammatory response in this context. As recently proposed, the observed elevated basal SOCS-3 and GSH levels could act synergistically as GSH can interact in SOCS-3 pathways to inhibit cytokines (Cisowski et al., 2002).

Besides its direct effect against oxidative stress, GSH may also act via the suppression of glia-mediated inflammation (Wang et al., 2006). In the same line with this idea, our contributions have shown that both UCP2 and SOCS-3 mRNA levels in brains infected with Toxoplasma gondii were elevated in microglia (Arsenijevic et al., 2007a). Although we cannot exclude a possible participation of infiltrated leukocytes, our evidence suggests that GSH, UCP2 and SOCS-3 may attenuate ischemic injury in infected mice by modifying microglia activity.

Despite a widely disseminated idea, only rare studies have shown that pre-existing infections can enhance brain pathology in response to a subsequent new inflammatory process (Arsenijevic et al., 1998). In contrast, several studies have shown that chronic infection can attenuate some peripheral and central pathological processes: complete Freund's adjuvant prevents the onset of experimental allergic encephalomyelitis (Bach, 2001), schistosomiasis can protect against asthma (Yang et al., 2007), coxsackievirus B3 can inhibit cardiomyopathy (Huber et al., 2006) and various infections can attenuate murine models of multiple sclerosis (Sewell et al., 2002). In some conditions, a pre-existing inflammation can induce brain neurodegeneration. This is the case for the acute peripheral and/or central injection of LPS (Nguyen et al., 2004; Cunningham et al., 2005; McColl et al., 2007; Qin et al., 2007; Spencer et al., 2007). However, it appears that the LPS dose used in these models may be a determinant in the observed degeneration. In fact, although high LPS doses may increase cytokines and oxidative stress, low doses of peripheral LPS have a neuroprotective effect (Bordet et al., 2000). This is consistent with our recent study in which we observed an increase in brain NGF and 
GSH levels 3 days after peripheral LPS treatment (Arsenijevic et al., 2007b; Hernadfalvi et al., 2007). In this context, the present study provides a new model to explore the effect of a pre-existing chronic inflammatory status on the outcome of brain ischemic insult. Since each bacterium or parasite produces different cytokine and leukocyte activation profiles and, ultimately, patterns of neurodegeneration, it is crucial to investigate the molecular mechanisms surrounding the beneficial or deleterious effect of various models of chronic inflammation on cerebral ischemia.

\section{CONCLUSION}

This study revealed a marked resistance of Toxoplasma gondii-infected mice to acute cerebral ischemia that is characterized by a decreased lesion size 1 day, 4 days and 14 days post-MCAO. Marked differences in pre- and/or post-ischemic cytokines and antioxidant molecules could explain this phenomenon. In addition, our findings imply that GSH may play a pivotal role in these processes since pharmacological depletion of GSH resulted in increased lesion size and increased brain IFN $\gamma$ levels. Functional neurological data could be useful to confirm further the protective effect of Toxoplasma gondii infection on the outcome of cerebral ischemia.

\section{REFERENCES}

Arsenijevic D, Clavel S, Sanchis D, Plamondon J, Huang Q, Ricquier D, Rouger L, Richard D (2007a) Induction of Ucp2 expression in brain phagocytes and neurons following murine toxoplasmosis: An essential role of IFN- $\gamma$ and an association with negative energy balance. J Neuroimmunol 186:121-132.

Arsenijevic D, Hernadfalvi N, von Meyenburg C, Onteniente B, Richard $D$, Langhans W (2007b) Role of nerve growth factor in the in vivo regulation of glutathione in response to LPS in mice. Eur Cytokine Netw 18:93-101.

Arsenijevic D, de Bilbao F, Giannakopoulos P, Girardier L, Samec S, Richard D (2001) A role for interferon- $\gamma$ in the hypermetabolic response to murine toxoplasmosis. Eur Cytokine Netw 12: $518-527$.

Arsenijevic D, de Bilbao F, Plamondon J, Paradis E, Vallet P, Richard D, Langhans W, Giannakopoulos P (2006) Increased infarct size and lack of hyperphagic response after focal cerebral ischemia in peroxisome proliferator-activated receptor $\beta$-deficient mice. J Cereb Blood Flow Metab 26:433-445.

Arsenijevic D, Garcia I, Vesin C, Vesin D, Arsenijevic Y, Seydoux J, Girardier L, Ryffel B, Dullo AG, Richard D (2000a) Differential roles of tumor necrosis factor- $\alpha$ and interferon- $\gamma$ in mouse hypermetabolic and anorectic responses induced by LPS. Eur Cytokine Netw 11:662-668

Arsenijevic D, Onuma H, Pecqueur C, Raimbault C, Manning BS, Miroux B, Couplan E, Alves-Guerra MC, Goubern M, Surwitt R, Bouillaud F, Richard D, Collins S, Ricquier D (2000b) Disruption of the uncoupling protein-2 gene in mice reveals a role in immunity and reactive oxygen species production. Nat Genet 26:435-439.

Arsenijevic D, Girardier L, Seydoux J, Chang HR, Dulloo AG (1997) Altered energy balance and cytokine gene expression in a murine model of chronic infection with Toxoplasma gondii. Am J Physiol 272:E908-E917.

Arsenijevic D, Girardier L, Seydoux J, Pechere JC, Garcia I, Lucas R, Chang HR, Dulloo AG (1998) Metabolic cytokine responses to a secondary immunological challenge with LPS in mice with T. gondii infection. Am J Physiol 274:E439-E445.
Auerhammer CJ, Melmed S (2001) The central role of SOCS-3 in integrating the neuro-immunoendocrine interface. J Clin Invest 108:1735-1740.

Bach JF (2001) Protective role of infections and vaccinations on autoimmune diseases. J Autoimmun 16:347-353.

Bate C, Kempster S, Last V, Williams A (2006) Interferon-gamma increases neuronal death in response to amyloid-beta1-42. J Neuroinflammation 3:1-7.

Bates S, Read SJ, Harrison DC, Topp S, Morrow R, Gale D, Murdock P, Barone FC, Parsons AA, Gloger IS (2001) Characterisation of gene expression changes following permanent MCAO in the rat using subtractive hybridisation. Brain Res Mol Brain Res 93: $70-80$.

Bjorkbaek C, Elmquist JK, El-Haschimi K, Kelly J, Ahima RS, Hileman S, Flier JS (1999) Activation of SOCS-3 messenger ribonucleic acid in the hypothalamus by ciliary neurotrophic factor. Endocrinology 140:2035-2043.

Bordet R, Deplanque D, Maboudou P, Puisieux F, Pu Q, Martin A, Bastide D, Leys D, Lhermitte M, Dupuis B (2000) Increase in endogenous brain superoxide dismutase as a potential mechanism of lipopolysaccharide induced brain ischemic tolerance. J Cereb Blood Flow Metab 20:1190-1196.

Brodie C (1996) Differential effects of Th1 and Th2 derived cytokines on NGF synthesis by mouse astrocytes. FEBS Lett 394:117-120.

Chen H, Luo J, Kintner DB, Shull GE, Sun D (2005) $\mathrm{Na}^{+}$-dependent chloride transporter (NKCC1)-null mice exhibit less gray and white matter damage after focal cerebral ischemia. J Cereb Blood Flow Metab 25:54-66.

Cisowski J, Zarebski A, Koj A (2002) IL-1 mediated inhibition of IL-6induced STAT3 activation is modulated by IL-4, MAP kinase inhibitors and redox state of HepG2 cells. Folia Histochem Cytobiol 40:341-345.

Cunningham C, Wilcockson DC, Campion S, Lunnon K, Perry VH (2005) Central and systemic endotoxin challenges exacerbate the local inflammatory response and increase neuronal death during chronic neurodegeneration. J Neurosci 25:9275-9284.

de Bilbao F, Arsenijevic D, Vallet P, Hjelle OP, Ottersen OP, Bouras C, Raffin Y, Abou K, Langhans W, Collins S, Plamondon J, AlvesGuerra MC, Haguenauer A, Garcia I, Richard D, Ricquier D, Giannakopoulos $P$ (2004) Resistance to cerebral ischemic injury in UCP2 knockout mice: evidence for a role of UCP2 as a regulator of mitochondrial glutathione levels. J Neurochem 89:1283-1292.

de Bilbao F, Guarin E, Nef S, Vallet P, Giannakopoulos P, DuboisDauphin M (2000) Cell death is prevented in thalamic fields by but not in injured neocortical areas after permanent focal ischemia in mice overexpressing the anti-apoptotic protein Bcl-2. Eur J Neurosci 12:921-934.

Droge W (2002) Free radicals in physiological control of cell function. Physiol Rev 82:47-95.

Eizenberg O, Faber-Elman A, Gottlieb E, Oren M, Rotter V, Schwarz $M$ (1995) Direct involvement of p53 in programmed cell death of oligodentrocytes. EMBO J 14:1136-1144.

Emsley HC, Tyrrell PJ (2002) Inflammation and infection in clinical stroke. J Cereb Blood Flow Metab 22:1399-1419.

Ewing JF, Janero DR (1995) Microplate superoxide dismutase assay employing a nonenzymatic superoxide generator. Anal Biochem 232:243-248.

Franklin KBJ, Paxinos G (1997) The mouse brain in stereotaxic coordinates, pp 29-41. San Diego: Academic Press Inc.

Frenkel JK, Escajadillo A (1987) Cyst rupture as a pathogenic mechanism of toxoplasmic encephalitis. Am J Trop Med Hyg 36: 517-522.

Guegan C, Ceballos-Picot I, Chevallier E, Nicole A, Onteniente B, Sola B (1999) Reduction of ischemic damage in NGF-transgenic mice: Correlation with enhancement of antioxidant enzyme activities. Neurobiol Dis 6:180-189. 
Guegan C, Ceballos-Picot I, Nicole A, Kato H, Onteniente B, Sola B (1998) Recruitment of several neuroprotective pathways after permanent focal ischemia in mice. Exp Neurol 154:371-380.

Gupta A, Gupta M, Datta M, Shkla GS (2000) Cerebral antioxidant status and free radical generation following glutathione depletion and subsequent recovery. Mol Cell Biochem 209:55-61.

Hernadfalvi N, Langhans W, von Meyenburg C, Onteniente B, Richard $D$, Arsenijevic D (2007) Role of glutathione in the hyposensitivity of LPS-pretreated mice to LPS anorexia. Eur Cytokine Netw 18:86-92.

Huang KC, Chen CW, Chen JC, Lin WW (2003) Statins induce suppressor of cytokine signaling-3 in macrophages. FEBS Lett 555:385-389.

Huber SA, Feidman AM, Sartini D (2006) Coxsackievirus B3 induces $\mathrm{T}$ regulatory cells, which inhibit cardiomyopathy in tumor necrosis factor-alpha transgenic mice. Cir Res 99:1109-1116.

Jo D, Liu D, Yao S, Collins RD, Hawiger J (2005) Intracellular protein therapy with SOCS3 inhibits inflammation and apoptosis. Nat Med 11:892-898.

Kang KE, Pak YMK, Kim ND (1999) Diethylmaleate and buthionine sulfoximine, glutathione-depleting agents, differentially inhibit expression of inducible nitric oxide synthase in endotoxemic mice. Nitric Oxide Biol Chem 3:265-271.

Larsen L, Ropke C (2002) Suppressors of cytokine signalling. APMIS 110:833-844.

Lebel E, Vallieres L, Rivest S (2000) Selective involvement of interleukin- 6 in the transcriptional activation of the suppressor of cytokine signaling-3 in the brain during systemic immune challenges. Endocrinology 141:3749-3763.

Lee J, Shin JS, Choi IH (2006) Human brain astrocytes mediate TRAIL-mediated apoptosis after treatment with IFN-g. Yonsei Med J 47:354-358.

Mattiasson G, Shamloo M, Gido G, Gido G, Mathi K, Tomasevic G, Yi $\mathrm{S}$, Warden CH, Castilho RF, Melcher T, Gonzalez-Zulueta K, Nikolich K, Wieloch T (2003) Uncoupling protein-2 prevents neuronal death and diminishes brain dysfunction after stroke and brain trauma. Nat Med 9:1062-1068.

McColl BW, Rothwell NJ, Allan SM (2007) Systemic inflammatory stimulus potentiates the acute phase and CXC chemokine responses to experimental stroke and exacerbates brain damage via interleukin-1 and neutrophil-dependent mechanisms. J Neurosci 27:4403-4412.

Murakami K, Kondo T, Kawase M, Li Y, Sato S, Chen SF, Chan PH (1998) Mitochondrial susceptibility to oxidative stress exacerbates cerebral infarction that follows permanent focal cerebral ischemia in mutant mice with manganese superoxide dismutase deficiency. J Neurosci 18:205-213.

Nguyen MD, D'Aigle T, Gowing G, Julien JP, Rivest S (2004) Exacerbation of motor neuron disease by chronic stimulation of innate immunity in a mouse model of amyotrophic lateral sclerosis. J Neurosci 24:1340-1349.

Nicholls DG, Budd SL (2000) Mitochondria and neural survival. Physiol Rev 80:315-360.

Park SH, Kim KE, Hwang HY, Kim TY (2003) Regulatory effects of SOCS on NF-KB activity in murine monocytes/macrophages. DNA Cell Biol 22:131-139.

Pileblad E, Magnusson T (1990) Effective depletion of glutathione in rat striatum and substantia nigra by L-buthionine sulfoximine in combination with 2-cyclohexene-1-one. Life Sci 47:2333-2342.

Qin L, Wu X, Block ML, Liu Y, Breese GR, Hong JS, Knapp DJ, Crews FT (2007) Systemic LPS causes chronic neuroinflammation and progressive neurodegeneration. Glia 55:453-462.

Sacco RL (2001) New risk factors for stroke. Neurology 57(5 Suppl 2): S31-S34.

Schulz JB, Lindenau J, Seyfried J, Dichgans J (2000) Glutathione, oxidative stress and neurodegeneration. Eur J Biochem 267: 4904-4911.

Sewell DL, Reinke EK, Hogan LH, Sandor M, Farby Z (2002) Immunoregulation of CNS autoimmunity by helminth and mycobacterial infections. Immunol Lett 82:101-110.

Spencer SJ, Mouihate A, Pittman QJ (2007) Peripheral inflammation exacerbates damage after global ischemia independently of temperature and acute brain inflammation. Stroke 38:1570-1577.

Villoslada P, Hauser SL, Bartke I, Unger J, Heald N, Rosenberg D, Cheung SW, Mobley WC, Fisher S, Genain CP (2000) Human nerve growth factor protects common marmosets against autoimmune encephalomyelitis by switching the balance of $T$ helper cell type 1 and 2 cytokines within the central nervous system. J Exp Med 191:1799-1806.

Wang JY, Wen LL, Huang YN, Chen YT, Ku MC (2006) Dual effects of antioxidants in neurodegeneration: direct neuroprotection against oxidative stress and indirect protection via suppression of gliamediated inflammation. Curr Pharm Des 12:3521-3533.

Wang J, Campbell IL (2002) Cytokine signalling in the brain: Putting a SOCS in it? J Neurosci Res 67:423-427.

Wang F, Wang LY, Wright D, Parmely MJ (1999) Redox imbalance differentially inhibits lipopolysaccharide-induced macrophage activation in the liver. Infect Immun 67:5409-5416.

Yang J, Zhao J, Zhang L, Yang X, Zhu X, Ji M, Sun N, Su C (2007) Schistosoma japonicum egg antigens stimulate CD4 CD25 T cells and modulate airway inflammation in a murine model of asthma. Immunology 120:8-18.

Yu L, Miao H, Hou Y, Zhang B, Guo L (2006) Neuroprotective effect of A20 on TNF-induced postischemic apoptosis. Neurochem Res 31:21-32.

Yu ZF, Mattson MP (1999) Dietary restriction and 2-deoxyglucose administration reduce focal ischemic brain damage and improve behavioural outcome: evidence for a preconditioning mechanism. J Neurosci Res 57:830-839. 